\title{
Acute shortage of children's nurses
}

The British Paediatric Association believes that Britain's sick children need many more specially trained nurses, and has issued a press statement to draw public attention to 3 recent reports on this subject. The BPA is concerned that there are not enough trained children's nurses, too few RSCN courses, and that few specially trained nurses stay in nursing. This problem is particularly serious in special and intensive care baby units.

The first of these reports by Dr Christopher Boothby (Suffolk) Children's wards and their nurse staffing in the UK found that 4 of every 10 wards were below establishment, that over one third of these wards had no trained children's nurses, and that half the wards had less than the minimum staffing level recommended by the Committee on Child Health Services (Court Committee). ${ }^{1}$

The report of the British Paediatric Association and the Royal College of Obstetricians and Gynaecologists Working Party, chaired by Dr Peter Dunn (Bristol)-Midwife and nurse staffing and training for special care and intensive care of the newborn ${ }^{2}-$ recommended that the minimum establishment in every 24 hour period should be 4 nurses or midwives for every intensive care cot and 1.25 nurses or midwives for every special care cot. This report was endorsed by the Royal College of Midwifery.

The third report by Dr Colin Walker (Dundee) Special and intensive care baby units and their nurse staffing in the $U K$ was published in the Archives in May of this year. ${ }^{3}$ Dr Walker concluded that only one third of these units met even the modest but essential staffing levels and that less than 1 in 10 intensive care units met the staffing recommendations of the BPA/RCOG report.

All 3 reports recommend that regional health authorities should coordinate facilities if the wide disparity between health districts is to be overcome and that the Department of Health and Social Security must take the initiative in this matter. Indeed a major survey published recently by the
DHSS Sick children's nurses: a study for the DHSS of the career patterns of RSCNs ${ }^{4}$ supports the BPA case.

\section{BPA recommendations}

As a result of these reports the BPA proposes that:

(1) All children should be nursed on children's wards.

(2) All sisters newly appointed to children's wards should hold the Registered sick children's nurse (RSCN) qualification.

(3) Regional health authorities should ensure that children's wards are adequately and appropriately staffed.

(4) Minimum staffing levels should be introduced for children's nurses and midwives for sick neonates.

(5) There must be more training courses for children's nurses and for nurses and midwivese looking after sick neonates in special and intensive care units. Health regions should be responsible for organising and funding sufficient training places so that services can be protected against local cutbacks.

(6) The DHSS should review health regions' plans each year to ensure national provision for sick children and babies is adequate.

These 3 reports are available free from the British Paediatric Association, 23 Queen Square, London WC1N 3AZ.

\section{References}

1 Committee on Child Health Services. Fit for the future. London: HMSO, 1976.

2 Standing Committee of the British Paediatric Association and Royal College of Obstetricians and Gynaecologists. Midwife and nurse training for special care and intensive care of the newborn; a discussion document. London: BPA/RCOG, 1981.

3 Walker CHM. Special and intensive care baby units and nurse staffing in the UK. Arch Dis Child 1983;58:387-92.

4 Hutt R. Sick children's nurses: a study for the DHSS of the career patterns of RSCNs. London: HMSO, 1983. 